Plant Tissue Cult. \& Biotech. 31(1): 109-114, 2021 (June)

(CBangladesh Assoc. for Plant Tissue Culture \& Biotechnology

ISSN 1817-3721, E-ISSN 1818-8745

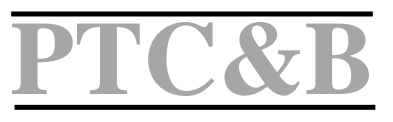

\title{
Studies on the Effect of Starvation on Prolonged Callus Cultures and Alterations in SERK Gene Expression during Somatic Embryogenesis in Momordica charantia Linn.
}

\section{Subhasree Das, Shonima Talapatra and Sarmistha Sen Raychaudhuri*}

Department of Biophysics, Molecular Biology and Bioinformatics, University of Calcutta, 92, A.P.C. Road Kolkata-700009, India

Keywords: Momordica charantia, Somatic embryogenesis, Histochemistry, SERK expression

Momordica charantia Linn. commonly known as bitter gourd is an annual climbing herb of Cucurbitaceae family. It is widely cultivated in Asia and South East Asia throughout India, Bangladesh and Thailand (Behera et al. 2011). It has been studied extensively for its medicinal properties in treating a number of diseases and traditionally used as antidiabetic and blood purifying agent (Joseph and Jini 2013). In somatic embryogenesis, embryo-like structures are derived from somatic cells other than gametes by evading the normal fertilization process, hence the offspring produced are genetically identical to their parent tissue (Feher et al. 2003). The switching of a somatic cell to an embryogenic state involves few changes in the composition of the cell wall. Periodic renewal of the culture medium is required, for maintaining the nutritional balance in the embryogenic cells (Raemakers et al. 1996). In somatic embryogenesis regulation, there is involvement of various genes and proteins at the molecular level and acquisition of embryogenic competence in somatic cells. Amongst all the genes, a novel gene named Somatic Embryogenesis Receptor Kinase (SERK) was first isolated by Schmidt et al. (1997) from carrot embryogenic cells, known as DcSERK. SERK gene acts as a molecular marker for somatic embryogenesis and its involvement in signal transduction and response against biotic and abiotic stress (Santos and Aragão 2009).

In this study, seeds of Momordica charantia Linn. variety Charantia of Murshidabad district, West Bengal were used to perform all experiments. Germination experiment was repeated for five times with 10 seeds each. Seeds of $M$. charantia were decoated and imbibed in sterile distilled water for overnight imbibition. Surface sterilization was done following the protocol standardized earlier in our lab by Paul et al. (2009).

*Author for correspondence: <sarmistharc@gmail.com>

DOI: https://doi.org/10.3329/ptcb.v31i1.54116 
The leaf explants excised from the germinated plantlets were then cultured in MS medium supplemented with $0.5 \mathrm{mg} / \mathrm{NAA}$ and $5 \mathrm{mg} / \mathrm{BAP}$. The callus cultures were maintained according to Talapatra et al. (2014). For studying somatic embryogenesis, histological sections were done with the calli of first passage and prolonged second passage and histology was performed as per Talapatra et al. (2014). Histochemistry was performed with only prolonged callus cultures. Polyclonal primary antibodies against SERK protein were commercially designed from IMGENEX Biotech, Bhubaneswar using protein sequence of MtSERK. The peptide sequence NLRTNLQDPNNVLQSWD was considered as the best epitope, which belonged to the leucine zipper region of SERK protein. FITC- conjugated goat anti-rabbit secondary antibody was used for primary antibody recognition. Localization of SERK protein in the callus sections of $M$. charantia was done by following the protocol designed by Paciorek et al. (2006).

Total RNA was extracted from $100 \mathrm{mg}$ each of 10-day old leaf, 21-day old first passage callus, and 80-day old prolonged second passage callus cultures using PureLink RNA Mini kit with minor modification (Talapatra et al. 2014). For relative mRNA expression pattern of SERK gene in leaf (Control), first passage and prolonged callus cultures of $M$. charantia, reverse transcription-PCR (RT-PCR) was performed using genespecific primers of McSERK gene such as forward (5'-GCTGTCCGTGGTACTATCG-3') and reverse primers (5'-TGGGGAGGTCATCTTGGA-3') respectively. The primer sequences and RT-PCR conditions were designed by Talapatra et al. (2014). For the normalization of the target gene expression, $\beta$-actin was used as an endogenous control and sequences of forward and reverse primers are: 5'-CATTCTCCGTTTGGACCTTG-3' and 5'-AGTTCTCTCTTTCATGTCACGC-3' respectively. The thermal reaction for RTPCR amplification of $\beta$-actin was the same as that of SERK. For the analysis of relative expression of McSERK transcript, real-time PCR was performed. First strand cDNA was synthesized from total RNA extracted from leaf, first passage, and prolonged callus cultures using RNA to cDNA kit. The SERK gene-specific primers were designed from sequence of $M$. charantia transcriptome (Accession No. JX863894.3) using Primer BLAST. The real time primer sequences of McSERK used were 5'-AGAACATACTTGGTAGGGG3' (forward) and 5'-ATACAAGCAGTCGTTCAGTA-3' (reverse). The qPCR conditions for MCSERK gene expression were maintained same as per Talapatra et al. (2014). $\beta$-actin gene was used as an internal control to normalize the fold change of SERK expression. The relative gene expression was performed using $2^{-\Delta \Delta C \mathrm{CT}}$ method according to Livak and Schmittgen (2001).

The sterilized seeds of $M$. charantia were aseptically transferred in jam jars containing agar-sucrose media for germination of the seedling which germinated within 10-12 days (Fig. 1A). Out of 10 seeds, 8-9 seeds were germinated after 10 days. Germination percentage was $90 \%(88 \pm 8.36)$. After 21 days of the first passage, the callus mass formed was green in color and globular structure of somatic embryos started forming in the callus cultures (Fig. 1B). Callus cultures in the second passage were kept undisturbed for prolonged period in the same media to observe the effect of starvation on inducing 
somatic embryos. Callus formed were green and pale yellowish in color, few cells incapable to survive died and turned brownish (Fig. 1C). Number of globular structure per $\mathrm{cm}^{2}$ of callus were found more in the prolonged second passage (35.8 \pm 3.37$)$ and less in first passage $(9.8 \pm 1.32)$. The histological study of the callus sections confirmed the initiation of somatic embryo and formation of globular structures in first passage with more embryogenic region. The cells had densely stained cytoplasm, small vacuole and nuclei (Fig. 1D). An initiating early stage somatic embryo was observed in the first passage callus section (Fig. 1E). In the prolonged cultures, non-embryogenic region was
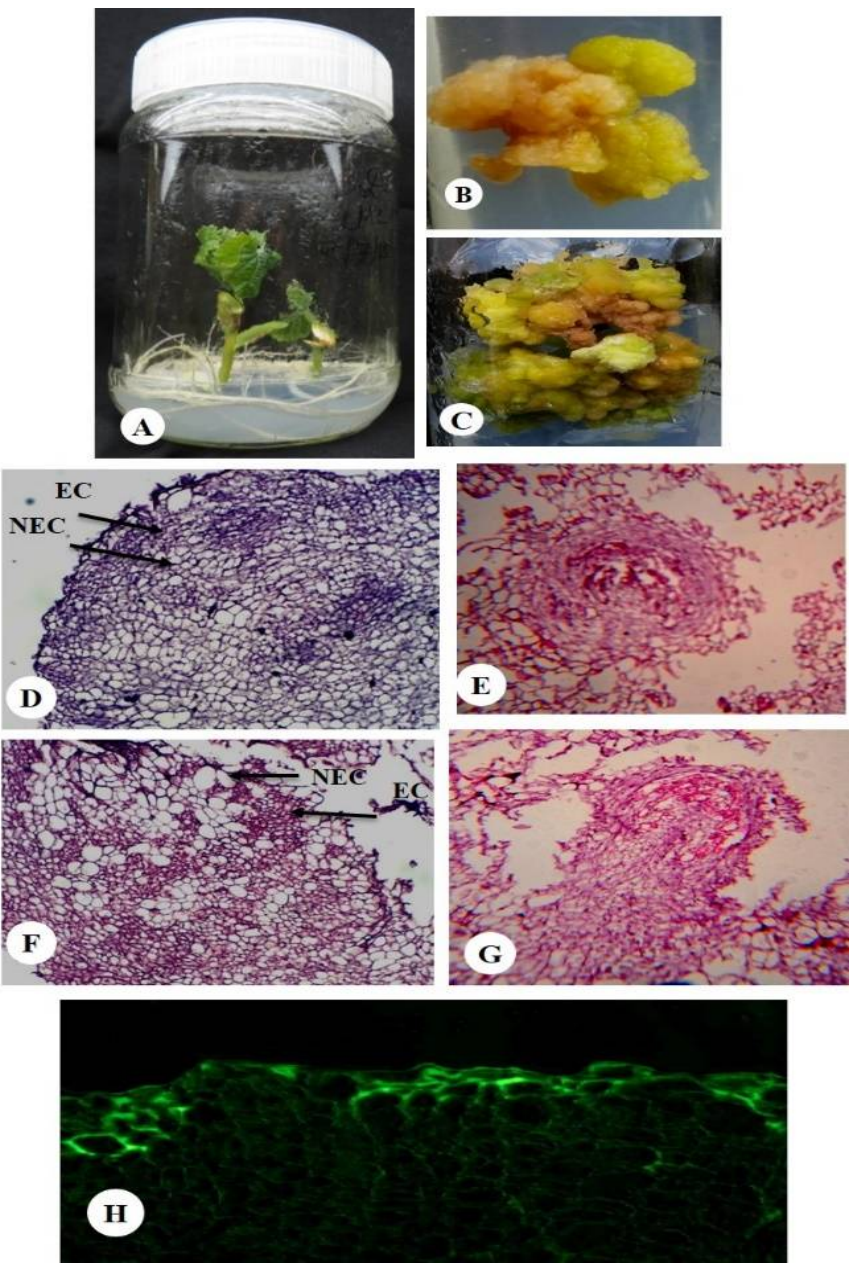

Fig. 1. (A) Germinated seedlings of Momordica charantia seeds after 10 days. Somatic embryogenesis of M.charantia in (B) First passage at $21^{\text {st }}$ day and (C) Prolonged second passage at $80^{\text {th }}$ day. Histological sections of (D) first passage callus culture, (E) initiating embryo in early stage (F) prolonged second passage callus culture showing embryogenic cells (EC), non-embryogenic cells (NEC) and (G) Globular shape somatic embryo. (H) Localization of SERK protein in histochemical sections of 80 -day old prolonged second passage culture of $M$. charantia in the embryogenic cells. 
characterized with the presence of large, elongated and vacuolated cells (Fig. 1F) and a globular somatic embryo (Fig. 1G) was observed in the peripheral region of the second passage callus tissue section. During in vitro culture, the formation of somatic embryo formation is a rare developmental process as somatic cells undergo dedifferentiation of cells, cell division activation and various changes in the expression pattern of associated genes (Feher 2015). Confocal microscopic analysis showed localization of Momordica charantia SERK protein in the embryogenic cell present in the peripheral regions of the tissue sections of 80-day old prolonged second passage callus culture (Fig. 1H). A number of studies reported that SERK is localized in the plasma membrane of embryogenic cells. Higher the fluorescence intensity indicates a higher accumulation of SERK protein in the callus tissue (Kedong et al. 2011).

Reverse transcription - PCR and densitometric data revealed that SERK gene expressed in all samples (Fig. 2A). Low level of SERK expression was detected in leaf samples in contrast to the first passage and prolonged callus cultures with an increased fold change of 1.06 and 1.2 respectively (Fig. 2B). The data showed a higher expression of SERK gene in the prolonged second passage cultures. $\beta$-actin acted as endogenous control and there was no altered change in $\beta$-actin expression. Real time PCR analysis observed an increase in fold change of 1.78 and 2.75 in the first passage and prolonged second passage respectively (Fig. 2C). Torres et al. (2015) reported in their study that peak expression recovery of SERK gene in Coffea arabica L. at 60th day embryogenic suspension culture was due to increased nutritional stress.

(A)

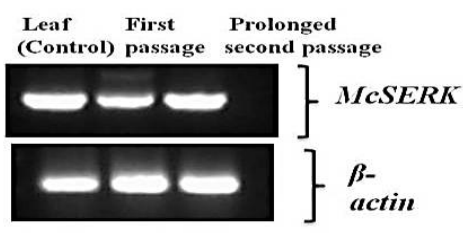

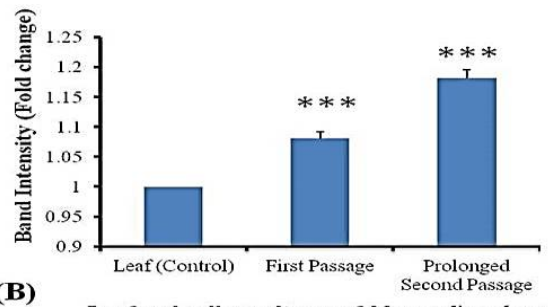

Leaf and callus cultures of Momordica charantia

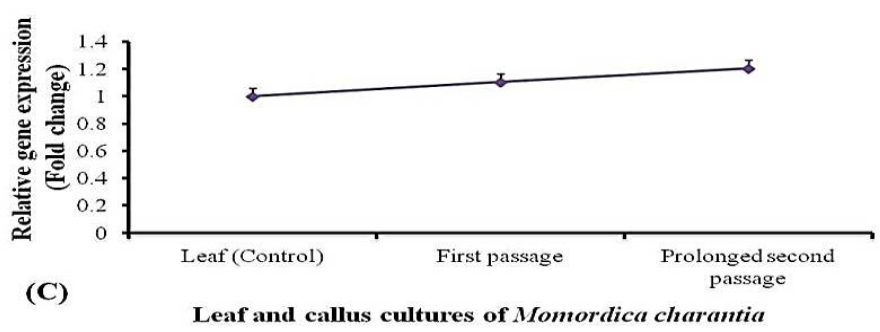

Fig 2. (A) Gel image of McSERK expression and $\beta$-Actin as endogenous control in leaf and different culture passages of M.charantia. (B) Graphical representation of densitometric analysis of band intensity by ImageJ representing the change in SERK expression. (The data are represented as mean \pm standard error of mean $(\mathrm{SEM})(\mathrm{n}=5)$. The level of significance denotes Asterisk; $\left.{ }^{*} \mathrm{p}<0.05,{ }^{* *} \mathrm{p}<0.01,{ }^{* * *} \mathrm{p}<0.001\right)$. (C) Graphical representation of Real-time PCR analysis showing alteration in the relative gene expression of SERK gene in $M$. charantia. (The data are represented as mean \pm standard deviation (SD) $(\mathrm{n}=3)$ ). 
In this study, starvation acted as an effective stress in the induction of somatic embryos. It was found that a little alteration in the micro and macronutrients under stress conditions altered the somatic embryo production. Densitometric analysis and real time PCR data documented higher MCSERK expression in the prolonged callus cultures which could be clearly correlated with the localization of SERK protein in the prolonged callus cultures. The high fluorescence intensity in the immunohistochemistry analysis provided the plausible explanation for localization of SERK protein paved new way into the functional role of SERK family proteins. Hence it could be concluded that nutrient supplementation and elevated level of SERK expression could play a crucial role in somatic embryo propagation and minimizing stress induced by starvation.

\section{Acknowledgement}

The first author (Subhasree Das) is greatly thankful and acknowledges University Grants Commission - Rajiv Gandhi National Fellowship for SC students (F1-17.1/201516/RGNF-2015-17-SC-WES-4026) in the award as Junior research fellow for the financial assistance.

\section{References}

Behera TK and Joseph John K, Bharathi LK and Karppaiyan R (2011) Wild Crop Relatives: Genomic and Breeding Resources Vegetable. Springer-Verlag, Berlin Heidelberg chapter 10Momordica. pp. 217-246.

Feher A, Pasternak TP, and Dudits D (2003). Transition of somatic plant cells to an embryogenic state. Plant Cell Tissue Organ Culture. 74: 201-228.

Feher A (2015) Somatic embryogenesis - stress-induced remodelling of plant cell fate. Biochimica et Biophysica Acta (BBA) - Gene Regulatory Mechanisms. 1849(4): 385-402.

Joseph B and Jini D (2013) Antidiabetic effects of Momordica charantia (bitter melon) and its medicinal potency. Asian Journal of Tropical Disease. 3(2): 93-102.

Kedong X, Qinglin L, Huifang Y, Li Z, Lili D , Fengluan L , Ling B , Nan M and Liangjun Z (2011) Isolation and molecular characterization of RCSERK1: A Rosa canina gene transcriptionally induced during initiation of protocorm-like bodies African Journal of Biotechnology. 10(20): 4011-4017.

Livak KJ and Schmittgen TD (2001) Analysis of Relative Gene Expression Data Using RealTime

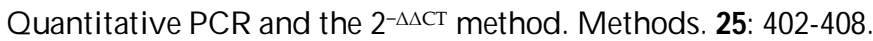

Paciorek T, Sauer M., Balla J, Wisniewska J and Friml J (2006) Immunocytochemical technique for protein localization in sections of plant tissues. Nature Protocols. 1(1): 104-107.

Paul A, Mitter K, Raychaudhuri SS (2009) Effect of polyamines on in vitro somatic embryogenesis in Momordica charantia L. Plant Cell Tissue Organ Culture. 97:303-311.

Raemakers CJJM, Sofiari E, Taylor N, Henshaw G, Jacobsen E and Visser RGF (1996) Production of transgenic cassava (Manihot esculenta Crantz) plants by particle bombardment using luciferase activity as selection marker. Molecular Breeding. 2: 339-349.

Santos MO and Aragão FJL (2009) Role of SERK genes in plant environmental response. Plant Signaling and Behavior. 4(12): 1111-1113. 
Schmidt ED, Guzzo F, Toonen MA and de Vries SC (1997) A Leucine rich repeat containing receptor-like kinase marks somatic plant cells competent to form embryos. Development. 124: 2049-2062.

Talapatra S, Ghoshal N and Sen Raychaudhuri S (2014) Molecular characterization modeling and expression analysis of a somatic embryogenesis receptor kinase (SERK) gene in Momordica charantia L. during somatic embryogenesis Plant Cell Tissue Organ Culture. 116: 271-283.

Torres LF, Diniz LEC, Livramento KGD, Freire LL and Paiva LV (2015) Gene expression and morphological characterization of cell suspensions of Coffea arabica L. cv. Catiguá MG2 in different cultivation stages. Acta Physiologiae Plantarum. 37(175).

(Manuscript received on 10/03/2021; revised on 30/05/2021) 